\title{
Zoos and the Breeding of Endangered Species
}

The valuable part that zoos can play in the breeding of endangered species as an aid to survival was made very clear at the conference on this subject held in Jersey early in May, for new techniques are making breeding increasingly easy for many species. But equally clear was how very small a part most zoos had in fact played so far, and how much needed to be done to change attitudes and improve communications between them, so that all zoos were willing to put the animals' welfare and breeding potential before rights of ownership and box office considerations.

All the zoo representatives who came to the conference - which attracted nearly 300 conservationists and zoo men from all over the world - came from zoos which had good breeding achievements to their credit and were willing and anxious to consider and put proved new techniques into practice. Basel Zoo, for example, is already breeding from 75 per cent of its mammals. One or two zoos could even claim the final accolade of having bred and returned endangered species to the wild - the Wildfowl Trust with the nene goose and the Pheasant Trust with the mikado and Swinhoe's pheasants. But such achievements are few so far, and one zoo representative, John Perry of the Washington Zoo, set the conference ball rolling with a series of figures, drawn from the International Zoo Yearbook, showing just how far zoos in general are in fact consumers of endangered species, even admitting, as he did, that the figures are incomplete, especially in the early years of the Yearbook.

The future is to be different! A declaration drawn up and discussed at the end of the three-day conference and unanimously agreed laid down that:

1 The breeding of endangered species and subspecies of animals in captivity is likely to be crucial to the survival of many forms. It must therefore be used as a method of preventing extinction, alongside the maintenance of the wild stocks in their natural habitats;

2 The techniques must be learned, improved, extended and published;

3 All who keep endangered species have a responsibility to carry out breeding programmes and to cooperate both with other zoos or collections for this purpose and with conservationists in returning them to the wild;

4 Such programmes will reduce the demands being made currently on wild populations and may serve to reinforce them, or, if they have disappeared in the wild, to re-establish them;

5 Even if re-introduction ultimately proves to be impossible, maintaining a captive population is obviously superior to the irrevocable alternative of extinction.

The conference, organised by the FPS and the Jersey Wildife Preservation Trust, which runs the excellent Jersey Zoo, whose Hon. Director is Gerald Durrell, was the first such international conference 'long overdue' was one speaker's comment - and it was generally agreed that a follow-up one should be held in the next two or three years. 